\title{
Sexism and permanent exclusion from school
}

\begin{abstract}
Focussing on narratives collected during a two year participant observation research project in the children's services department of an urban local authority, this article addresses the intersection between incidents of permanent exclusion from school and assumptions made of the basis of a young person's gender. The article will consider gendered class reproduction through the choice of GCSEs; gender normativity in single sex schools; and the relationship between domestic violence and sexual aggression in incidents of school exclusion. It will finish with an account of some of the work being done to develop the professionals' support strategies and young people's self-management skills necessary to tackle these effects.
\end{abstract}

\section{Introduction}

This article will address the ways in which a permanent exclusion from school can reveal an undertow of institutional sexism. Permanent exclusions represent a critical moment in a young person's school career and in their life, and looking at them in detail can reveal much about what is wrong with a system ostensibly dedicated to inclusive education.

The article focuses its attention on an urban local education authority, 'Enway'. During three years working with excluded children in Enway, I collected a range of case studies and narratives, and it is these which will form the basis of the article. Comparing some of the assumptions and pressures around gender identity raised in Enway's mixed and single-sex schools will provide a crystallised illustration of some of the effects of gender normativity in school. The following sections will focus on gendered class reproduction through the choice of GCSEs; and on 'horizontal violence' (Freire (1996)) in schools manifested as sexual aggression. The conclusion will clarify some of the links between gender normativity and instances of threatened or actual permanent exclusion, finishing with an account of some of the work already being done in Enway to develop support strategies and self-management skills designed to tackle these effects.

\section{'Deviant' and 'troublesome'}

The role of conceptions about gender in schools in England and Wales is broadly discussed in educational studies literature. Underpinning anxieties about the 
underperformance of boys, for example, the theory of 'the feminisation of education' is concerned with the idea that there are not enough male teachers and that as a result, schools, curriculum and teaching and assessment styles are more appropriate to the learning styles of girls (Wright (2005)). However, ' ...the behaviour of girls continues to be policed in ways that the behaviour of boys is not. They are ascribed labels such as 'deviant' and 'troublesome' by professionals...sexuality is central to the definition of 'troublesome' in relation to girls' (Lloyd 2005 (p.5)). This may be especially marked with regard to girls from some ethnic minority backgrounds; Wright (2005) has described '...teachers' construction of young black females as 'marginalised' and troublesome 'others'”(p.104) (see also Lloyd (2005), Francis (2005)). Boys, on the other hand, tend to ‘...dominate classroom space' (Francis (2005), p.10). However, black (especially Caribbean/British) boys in English education were long the group least likely to acquire adequate GCSE grades (Gaine and George (1999), Wright (2005), Rendall and Stuart (2005)) $)^{1}$. More boys are excluded than girls, and more boys and girls from ethnic minority backgrounds are being permanently excluded than British-born white pupils (Wright (2005), Timimi (2005), Wright et al (2000), Rendall and Stuart (2005)), although this data does not include any kind of focus on Traveller children. Wright (2005), writing on black femininities in school, explains that '...within educational contexts that are normatively gendered, classed and racialised, issues of embodiment can become problematic...' (p.105). Socioeconomic class also interacts with constructions of gendered behaviour, with working-class girls, for example, often seen as '...over-sexualised and over-assertive, referred to variously by teachers as “'little cows' and 'real bitches”' (Francis (2005), p.11). The literature has identified schools as institutions that are prone to be run along lines that involve a normed version of what it means to behave 'like a girl' or 'like a boy' with specific variations according to perceived ethnicity and cultural/economic background. Permanent exclusion, with its 'critical incident' quality, is a useful lens through which to focus attention on challenges to inclusion, including those concerned with gender.

\footnotetext{
${ }^{1}$ Although in Enway white British working class boys are now the group least likely to achieve 5 GCSEs at grades $\mathrm{A}^{*}$ to $\mathrm{C}$
} 
The pupil's vulnerability to gender stereotyping at points of transition

In Enway, pupils at risk of or subject to a permanent exclusion usually find themselves having to transition- sometimes many times- between schools and/or alternative education placements. Sitting on plastic chairs in the office of a head of year or an inclusion manager, at the reintegration meeting- the initial interview where I often met pupils and parents for the first time, and which constituted the moment of transition into a new school- pupils and parents in Enway schools were asked to complete a stack of 'admission forms'. Balancing the forms uncomfortably on their knees whilst the inclusion manager reclines behind a large battered desk, parents and carers filled out the pupil's name and address, contact telephone numbers, birth date and assigned gender, ethnicity and home language. The pupil was thus ascribed an institutional identity through this series of 'fixed' word-labels.

The Enway 'Hard to Place' Pupil Placement Panel represented another of the transition stages through which a pupil at risk of permanent exclusion must travel and at which she or he must be described and identified in order to be placed at a new school. It consisted of a large group of head teachers, special educational needs officers, admissions, attendance, youth offending and inclusion managers, and social workers. Every two weeks 'the Panel' sat around a long group of school tables in a broken council building and discussed Enway's transitioning children. These children were seeking new schools because they had been excluded, bullied, placed in foster care or under police protection, left a young offender's institution, or recently arrived from another country as an asylum seeker. Names, year-groups and gender identity were recorded multiple times in the Panel paperwork. Social, behavioural and emotional histories were also summarised in scratchy photocopies of school behaviour logs and social workers' reports. In the absence of the young people and their families, Panel members often also described behaviour without the social restraint that might be expected if family members were present. And behaviour was often described in relation to normative ideas about the appropriate embodiment of gender. 
For example, April, a Year $9^{2}$ pupil at risk of permanent exclusion, had been attending Newhall School and had been experiencing some difficulties with managing her anger in class. Her mother had taken her to the doctor and she had been told that this anger was symptomatic evidence of an extreme form of pubescent pre-menstrual syndrome (PMS). At school, April had been told that she would have to accept a managed move or be permanently excluded.

'She has not very supportive parents', announced one of the head teachers at the Panel meeting, 'and she is a person who puts herself in trouble. There is some sort of collusion that goes on between April and her mum. She's a big abusive girl, I mean she's big...'

'She may have the right to choose (her school placement)', responded another head teacher who had never met April, 'but she will cause major problems at mainstream³.' April's behaviour record showed that she had lost her temper with teachers a few times, and had been in a couple of small fights with other girls. This is a good example of the normative expectations of girls' 'appropriate' behaviour often exhibited at the Enway Panel; boys referred for placement who are at risk of permanent exclusion always have more than a couple of fights and a bit of a temper tantrum on their behaviour logs. But April was placed at a new school, Enway Valley, and I planned a reintegration meeting for her, wondering if I would meet a 'big abusive girl', as reported.

When I met April for the interview a few days later, I saw that she was actually quite average in size. She was perhaps taller than some of her peers, but she was well within the current range. She was not abusive in the meeting, either, but smiled shyly, hiding behind her blonde hair. She talked about being at her old school; I knew that at that particular school, teachers were struggling to maintain control of the classes and there had been many reports of bullying.

A few weeks later, April was asked to leave Enway Valley due to 'rudeness'. As a result of the failed managed move, following the established protocol, she was then permanently excluded from Newhall. However, she finally settled down at another school, and at the time of writing was still attending, with no exclusions or fights on her record.

\footnotetext{
214 years old

${ }^{3}$ That is, in a mainstream school, implying she would do better at an alternative education placement
} 
April's story exemplifies the connection between the embodiment of gender identity, and the vulnerability to imagination and description by others. Her angry behaviour at Newhall School and her 'rudeness' at Enway Valley were possibly in part a result of the chaotic environment and the pre-menstrual hormones coursing through her body. However, I would argue that this did not appear to fit with how the head teacher describing her at the Panel thought a girl, embodied, should comport herself, normatively attributing her 'transgressive' (aggressive) behaviour to her existence as 'a big, abusive girl'. Not actually 'big', and despite medical and contextual evidence providing the Panel with the choice to adopt a reasonable explanation, April had been seen to have transgressed acceptable parameters for a girl, and her physical body had then been described in terms of an instance of her behaviour- what I would call her 'extended (imagined, describable) body'. Of course, the PMS diagnosis could also be seen as a pathologising deficit-oriented description applied to April's 'extended body'. But it was a narrative deselected by the Panel in exchange for assumptions made on the basis of April's gender identity. I had to travel with April and her mum through three transitions- two reintegration interviews and a permanent exclusionchallenging received narratives about a 'big, abusive girl' before she was able to settle down at her final school.

\section{The 'trouble' with girls...}

Perhaps because of abiding understandings identified in the literature about 'the relationship between young women and sexuality and the ways in which this relationship may be constructed as 'trouble”' (Lloyd 2005 (p.191)), the Enway Panel delegates were particularly prone to adopting gendered narratives about pupils' extended bodies when they were discussing instances of non-consensual sexual contact and sexual aggression between young people. For example, a fourteen-yearold boy was being discussed following his permanent exclusion from a school in a neighbouring city for, as the brief paperwork described, '...touch(ing) a girl's bottom'. There was a hint of male sniggering at this, and one head teacher at the Panel asked whether this was ‘...just that he touched a girl's bottom or more...?' By the word 'just', the boy's behaviour was thus normatively validated as acceptable. The women around the table rolled their eyes in disgust, but did not challenge the head teacher. However, when a girl's behaviour later at the same Panel meeting was described by one of the delegates: 
'She won't leave the boys alone, pulling their trousers down...'- a (female) head teacher querulously responded,

'...we have evidence of inappropriate sexualised behaviour... what assessments are being made of her as not a victim, but a perpetrator? ...A psychiatric assessment (is needed) in Enway Mental Hospital School...' This pupil, Rachel, was discussed at the Panel several times, offering plenty of opportunities for the delegates to pronounce upon conceptions of her behaviour in relation to her gender identity and her sexuality. She was thus described as dangerous in terms of her sexuality (and described as 'wild' by one of her teachers when discussing the pulling down of boys' trousers); at great risk in terms of the physical features of her gender identity (of rape as a gang initiation strategy) and as vulnerable in terms of her gender-role (as a carer for her mother and baby siblings). It is of course not acceptable for any pupil to nonconsensually pull down the trousers of another. But the range of consequences available span from verbal redirection or detention to a fixed-term or permanent exclusion, and I would argue that the Enway Panel's acute reading of the case was framed around the 'fact' that Rachel is 'a girl'.

\section{Single-sex schools}

In looking at the institutionalised treatment of gender in educational contexts, it is telling to pay closer attention to the difference between single- and mixed-sex schools.

At Forrest Boys, the only boys' school in Enway, one of the teachers told me that she had lived 'in a constant state of shock' when she had first started teaching there. She said that she had only worked in girls' or mixed schools before, and that her shock had been at the 'physical' way in which some of the Forrest teachers treated the pupils. They would casually slap pupils on the back of the head as they went past in the corridor; were usually less than sympathetic if a pupil hurt himself; and if the head teacher, prowling the corridors, found a pupil who was 'bustin' low', he would shout his objection in a loud Glaswegian accent and then pick him up by the waistband and shake him down into his trousers. I would argue that the nature of unmistakeably being labelled 'a boy', with all the normed expectations of 'boyness'-

\footnotetext{
${ }^{4}$ Wearing his trousers pulled down so the waistband goes across the buttocks in a trend popularised in part by American hip-hop and rap music videos
} 
for example, ability to withstand physical hardship- is an inexorable result of attending a boys' school. Thus as happens with the 'power of language', this sexual difference label 'enacts physical and material violence on bodies' (LeBesco (2001 (p.76)).

In contrast to the single boys' school, there are three girls' schools in Enway. Enway Valley School for Girls is known to have 'a very difficult Year 10', having taken several permanently excluded girls from Dunthorpe School, just across the border in a neighbouring and equally deprived city. The 'Dunthorpe Girls’ seemed to have taken on a reputation of their own. At the Panel, if someone described a pupil as 'a Dunthorpe Girl', the head teacher delegates all assumed that she would be a loud, disruptive black girl who was very likely to cause mayhem and disorder if she was reintegrated into one of their schools. This is obviously problematic, as each case is not then taken on its merits but received encumbered with a 'raced' and 'gendered' narrative of a transgressive 'extended body'. Enway Valley has also taken several of the 'vulnerable' girls at risk of exclusion from the nearest mixed school. In existing as a single-sex environment, then, Enway Valley, a small mainstream school, has found itself being expected to provide automatic succour for large numbers of 'troubled' girls.

By contrast, Appledown Estate School is the largest school in Enway. It is a girls' school with a mixed sixth-form in a largely working class white British and Somali area, and the uniform has been altered to allow for the long skirts and hijab head coverings of some of the Muslim girls. These are cut from the same dark blue cloth as the non-Muslim girls' shorter uniforms and are won with the same bright blue shirts. The school is distinctive in this respect, being the only one in Enway where the uniform is expressly available in short or long hijab-appropriate versions. In other schools, girls who wear the long skirt and hijab head covering put on a plain black or white one and fit it in with or under the available regular uniform. The effect of the blue hijab head covering and long skirt- young womens' Muslim dress officially validated through its availability in school colours- is to make Appledown Estate look more welcoming to Muslim girls and their families, and open-minded to all. With the institutional mandate expressed in uniform rules, the intersection between cultural background and gender becomes accepted and normed. 
A further example of the norming effects of a uniform is to be found at Maria Magdalen Convent, Enway’s Catholic Girls’ School. Maria Magdalen pupils wear an embroidered badge on their school coats emblazoned with a large golden cross. The school justifiably prides itself on its inclusive intake protocol, a tight behavioural control over its pupils based on Catholic ethics, and an annual set of high exam results. The teachers there are usually very good at implementing de-escalation strategies, but one girl I was working to settle in to Maria Magdalen lost her temper after being written up on a 'pink detention slip' for 'rolling her eyes' at a teacher. It could be argued that this was seen as behaviour transgressing interacting expectations of religion and gender: an example of the problematic potential of the gendered 'embodiment' (Wright 2005 (p.105)) of 'the good Catholic girl'.

If the single-sex schools in Enway present particular limits with regard to normed expectations around 'gendered behaviour', what happens at a mixed school? Gaine and George (1999) explain:

...early supporters of co-educational schooling (in the 1920s) saw this form of schooling in terms of the many advantages it held for boys: a reduction in homosexuality amongst the boys; boys' behaviour would be less rough because of the 'civilising influence' of girls; the replication of family-like relationships would contribute to bringing about healthier marriages.

p. 131

By the 1970s, mixed schools were seen to be the most appropriate option in terms of gender equality,

...giving girls the benefits of the kind of education more often reserved for boys (as well as giving the boys the benefits of the girls' 'civilising influence') ... ibid

In Enway, however, and despite these hopes for girls' 'civilising influence', almost all of the mixed schools have been the sites of several incidents of sexual aggression against girls, occasionally resulting in the permanent exclusion of the (almost 
exclusively) boys responsible - many of whom are placed at the mixed Pupil Referral Unit (PRU). The Panel is often reluctant to steer 'vulnerable' girls towards the PRU. New Start, Enway's alternative education provision for those deemed 'too difficult' for the PRU, is also mixed, but mainly populated with boys. So girls who have experienced male sexual aggression and who are non-attenders or who display angry and /or aggressive behaviour themselves are often designated 'vulnerable in the presence of boys' and placed at the mainstream girls' schools. The problem with this is that in the two smaller mainstream girls' schools, girls are less likely to have access to the listening, support and self-esteem-building brief of school Learning Mentors, as there will be less funding available for such services. Being placed at mainstream school, they will also miss out on the chance of the small-group therapeutic selfmanagement strategy training offered at most of the alternative education provisions, necessary if they are to offer a contention for power in the contested space of their own gendered 'extended bodies'.

Anzaldua (1987) conceives of borderland spaces as places 'wherever two or more cultures edge each other' (p.26). However, without trying to essentialise or dichotomise the 'group experiences' of 'girls' and 'boys', I think it is useful to understand mixed-gender schools, where fairly established groups of boys and girls at least intersect, as generating a similar 'borderland' experience. Anzaldua (1987) describes her experience of being a member of the non-dominant population (a Mestiza Texan woman) as one of choosing to 'abnegate'- to stay quiet and suffer- or to make a choice to 'take control' (p.43). If this framework of existence is transposed onto the experience of girls within a mixed school, it is possible to see that those girls who are experiencing difficulties may be pushed into either abnegationdisengagement and truancy- or into a wobbly adolescent version of 'taking control'which may result in behaviour which is seen as 'too aggressive (transgressive) for a girl'.

\footnotetext{
${ }^{5}$ See below under the sub heading 'Sexualised behaviour; sexual aggression and violence' for a more detailed discussion of this phenomenon
} 


\section{Choosing GCSEs: the gendered reproduction of class}

In addition to a reduction in available support, the Enway pupils who find themselves inadvertently in single-sex schools due to an exclusion or a 'managed move' ${ }^{6}$ usually find themselves being offered a reduced choice in terms of curriculum, directly related to gender normativity. For example, just one of the three girls' schools provides encouragement for girls to do engineering- or construction-related courses, and Forrest Boys declines to offer its pupils 'Hair and Beauty' or any kind of training related to a care vocation. Thus the gendered 'choices' girls and boys make with regard to the vocational and/or academic courses they take in Years 10 and 11 can be seen as related to a reproduction of class in school (Bourdieu (1977)).

During reintegration meetings with pupils who were moving (due to an exclusion or a 'managed move' in the middle of Year 9 or during Year 10- at the stage where they need to choose their GCSEs- I noticed that the mixed schools tended to funnel their lower-achieving $^{7}$ girls into 'Animal Care', 'Hair and Beauty', and 'Social Care' vocational courses, whilst their lower-achieving boys tended to be directed towards 'Construction' and 'Public Service' ${ }^{8}$ tracks. A girl who wanted to take a construction course would of course be verbally encouraged to do so, where it was available- but she would find herself transgressing normed boundaries, and the task of building the self-esteem and courage it would take to do this constitutes a barrier in itself. In any case, as Francis (2005) has identified, 'tendencies in mixed-sex classrooms (include)... the ways in which some boys monopolise physical and verbal space, and the ways in which girls tend to defer to boys' (p.9), so a girl taking a Construction course would need to be able to challenge these difficulties as well. Similarly, I never came across a boy who voiced a desire to join the Hair and Beauty or Social Care cohorts- although some heads of year joked about this in reintegration interviews with their new male pupils, invoking a mocking chauvinist humour and ridiculing any boy's genuine desire to gain these skills. In any case, reintegration meetings for pupils who came with a behaviour log full of transgressions were always focussed more on the behaviour (the past) than on GCSE choices (the future), and so that part

\footnotetext{
${ }^{6}$ 'Managed moves' are intended to be a 'fresh start' for young people at risk of exclusion. But because permanent exclusions attract a large financial penalty, schools often 'threaten' young people with exclusion if they do not accept a 'managed move'.

${ }^{7}$ As in most schools in England and Wales, 'achievement' is measured in Enway schools by academic level

${ }^{8}$ Army, police, fire service, etc.
} 
of the meeting was often rushed, crammed as it was into the last few minutes. I often struggled to interject on behalf of the pupil to promote their views on the choices, and parents frequently agreed to their child being placed on courses relative to their own line of work- in the building trades, for example. I would ask the child a question about their GCSE choices, and the head of year or parent would regularly answer for them. Because of this, gendered curriculum 'choices' are more likely to be pushed through without the extensive weeks-long period of guided research, parents' meetings and career consultations afforded to most pupils who are making their Key Stage 4 decisions. Thus through the effects of the transitional process undergone by pupils at risk of or subject to a permanent exclusion, girls and boys who are already disadvantaged by these circumstances are directed to reproduce their parents' gendered economic experiences. Being given a place in the family business can be a beneficial outcome, and there is nothing wrong per se with choosing to become a hairdresser or a builder- but the Key Stage 4 Options-choosing procedure would be more empowering and less gender-norming for the pupil if it at least provided the opportunity to think through the options.

\section{Sexualised behaviour; sexual aggression and violence}

Sexualised behaviour formed the basis of the discussion around several of the cases brought to the Enway Pupil Placement Panel: Rachel, for example, who was discussed as needing to go into the Enway Mental Hospital School. In April 2007, another pupil, Mahad, was permanently excluded for a sexual assault, resulting in a court case and an eighteen month control order with the Youth Offending Team. Further cases of sexual aggression and violence began to arise in Enway as 2007 turned into 2008.

In March 2008 a girl was discussed at the Panel. She had been permanently excluded for using her mobile phone to video and subsequently post online footage of a sexual assault. In May, during a discussion around whether another girl should go to a mixed school, one of the Panel head teachers cautioned, '... we all know that some of the Enway Boyz (a local 'gang', some of whose members attended the school under discussion) are heavily involved in rape as an initiation...is she vulnerable...?' By the end of the year, at one of the other mixed schools, the head teacher had been forced to resign, the behaviour management situation becoming so bad that scores of girls were 
truanting following threats of rape by boys at the school. Several of the boys were finding themselves on the sex offenders register as a result. I and many of my colleagues felt that the situation was out of control; we felt out of our depth. We could not understand it. Why was all this happening in Enway?

\section{Sexual and domestic violence: Horizontal violence}

Sexual violence in Enway schools seems to me to be a form of what Paulo Freire (1970) calls the 'horizontal violence' (p.44) demonstrated by people living within an oppressed society. According to this theory, oppressed people tend to try to adjust their hierarchies and to assert their self-worth in struggles with each other, unable to strike out at those in power. I would suggest that sexual violence within the school context constitutes a version of this 'horizontal violence', its sexual nature instigated and exacerbated by gendered inequities. It follows that researching and tackling these inequities should result in a reduction of 'horizontal violence' in schools. Examples of these inequities include the high proportion of black African-Caribbean and white working class boys being excluded or moved; the invisibility of pupils' lesbian, gay and transgendered identity issues in Enway professionals' discussions about support planning; the gender-stereotyped vocational course 'choices' available to pupils in Enway's mixed and boys' schools; the poverty experienced by children living with single mothers (Ridge 2005 (p.24)); and the proliferation of domestic violence in Enway witnessed by young people at risk of or subject to a permanent exclusion.

Domestic violence towards mothers featured in almost all of those of my cases which involved permanent exclusion for violent behaviour. One boy in this situation, Billy, started at Knightsdown College, the largest mixed comprehensive school in Enway, after Sandy, his mother, took him out of a chaotic, failing school in the neighbouring district of Prosper because he was at risk of permanent exclusion for fighting. She had been through a very serious period of domestic violence, including several hospitalisations; Billy's father was now in prison, but Sandy was still deeply affected by what she had been through. Like the other mothers I worked with in Enway who had been subjected to domestic violence, Sandy felt unable to rouse the strength she needed to draw firm boundaries at home, and felt very guilty about what she saw as failing to protect her children from witnessing the violence. For example, she was unable to insist that Billy took his diabetes medication, and had a difficult time 
standing her ground around issues such as homework and getting the children up and ready in time to get the bus to school. Gender inequity in this case was a central feature in the circumstances leading to Billy's school threatening him with permanent exclusion.

\section{Conclusion}

I suspect that some permanent exclusions from school happen because of habitual assumptions about pupils and their families and a lack of knowledge of the grinding chronic inequities they can suffer. Gender is a useful prism through which to investigate this problem because its inexorable 'biological' reputation stretches the limits of stereotype deconstruction. Normed, fixed and essentialised understandings about gender and its interaction with class, ethnicity and identity have a profound and complex effect on judgements made about pupils at risk of or subject to a permanent exclusion. In addition, many of the incidents leading to permanent exclusions and managed moves in Enway involved a gendered 'horizontal violence' (Freire (1977)) component.

I do not think that most of the teachers and other professionals who are involved with inclusion and exclusion at school deliberately make negative judgements about pupils on the basis of their gender identities. However, as Hoy (1999) states, '(w)e tend to prefer the familiar that we have already coped with and we build up non conscious, unwilled strategies for avoiding the perceptions of other possibilities...' (p.15). Teacher fatigue in the face of multiple administrative, financial and emotional pressures must play a part in the development of this habit of avoidance. But this is not an inevitable state of being, and I think that there is a space for the exertion of professional agency in the idea that this habit ${ }^{9}$ does have '.... degree of plasticity...' (ibid, p.14).

Thus some Enway Children's Services and school staff are reflective and responsive about the problems experienced by young people, at risk of or already permanently excluded, with regard to assumptions made about their gender identities. On the wall

\footnotetext{
${ }^{9}$ Related to Bourdieu's (1977) concept of 'habitus'
} 
of the concrete stairway up to the Enway Inclusion and Appraisal Unit, a Boys' Group is advertised, promoting

...self-awareness, self-development, personal hygiene, socially acceptable behaviour, body image, sexuality, role models, social skills, basic skills, life skills, friendships, life-choices, careers, learning and enjoyment.

Some of these factors, depending on the degree to which they are sensitively delivered by the convenor of the Boys' Group, have the potential to undermine boys' empowerment through self identity. For example, the plan to promote role models involves the risk that they may all be 'normed male' role models; social skills have the potential to be taught in a stereotypically gendered way. However, the fact that this discursive space has been opened up at all provides the opportunity to teach selfmanagement skills and sensitive to stereotypes made about gender. Mahad, for example, whose mother was in prison, may have benefited from this Boys' Group; it may have helped him to understand and keep to the socially appropriate boundaries of personal space between boys and girls.

If schools are understood to be as institutions which reproduce the social order (Bourdieu (1977), Freire (1996), Lawrence-Lightfoot (2003)), then they must be understood as institutions which are bent towards reproducing the 'normed' gendered aspects of this. And, I would argue, part of the expression of administrative power through this normalising process requires recourse to '.. performative exclusions that mark the threshold of the abject' (Weiss 1999 (p.50)). Those working to support pupils at risk of or subject to a permanent exclusion from school- pupils such as Mahad and Billy whose personal circumstances, some of which are linked to the interactions between gender, ethnicity and cultural background, have them living in a state of survival or resistance (Anzaldua (1987), Freire (1996))- need to take into consideration the idea that they will be especially vulnerable to abjection through the inequitable results of this norming process.

\section{Bibliography}

Andalzua, G (1987) Borderlands: La Frontera - The New Mestiza San Fransisco: Aunt Lute Books 
Blackman, L (2001) Hearing Voices: embodiment and experience London: Free Association Books

Bourdieu, P and Passeron, J (1977) Reproduction in Education, Society and Culture London: Sage Publications

Butler, J (1999, first published 1990) Gender Trouble Routledge: London

Butler, J (1993) Bodies that Matter: on the discursive limits of "sex" London: Routledge

Cooper, C (2002) Understanding school exclusion: challenging processes of docility Nottingham: Education Now Publishing Cooperative

Csordas (1999) “Embodiment and Cultural Phenomenology”. In Weiss, Gail, and Haber, Honi Fern. Perspectives On Embodiment, Routledge, New York and London.

Foucault, M (1977) Discipline and Punish Harmondsworth: Penguin Books (Trans. Alan Sheridan)

Francis, B (2005) Not/Knowing their place: Girls’ classroom behaviour in Lloyd, G (Ed.) Problem Girls: Understanding and supporting troubled and troublesome girls and young women Oxon: RoutledgeFalmer

Freire, P (1996) Pedagogy of the Oppressed London: Penguin Books

Gaine, C and George, R (1999) Gender, "race", and class in schooling London; Philadelphia, PA : Falmer Press

Giddens, A (1986) The Constitution of Society Oxford: Blackwell Publishing Ltd

Lawrence-Lightfoot, S (2003) The Essential Conversation: What parents and teachers can learn from each other USA: Random House 
LeBesco, K (2001) Queering fat bodies/Politics in LeBesco, K and Braziel, JE (Eds) Bodies out of bounds: fatness and transgression London: University of California Press

Moore, H (2007) The Subject of Anthropology Cambridge: Polity Press

Rendell, S and Stuart, M (2005) Excluded from School: systemic practice for mental health and education professionals, Hove:Routledge

Ridge (2005) Feeling under pressure: low-income girls negotiating school life in Lloyd, G (Ed.) Problem Girls: Understanding and supporting troubled and troublesome girls and young women Oxon: RoutledgeFalmer

Rose, N (1999) Governing the Soul: The shaping of the private self (2nd Ed) London: Free Association Books

Timimi, S (2005) Naughty Boys: anti-social behaviour, ADHD and the role of culture Basingstoke: Palgrave MacMillan

Wright, C (2005) Black femininities go to school: how young black females navigate race and gender in Lloyd, G (Ed.) Problem Girls: Understanding and supporting troubled and troublesome girls and young women Oxon: RoutledgeFalmer

Wright, C, Weekes, D and McGlaughlin, A (2000) 'Race', Class and Gender in Exclusion from School London: Falmer Press

11616 words (not including bibliography and footnotes) 